\title{
Clinical and economic considerations of antiobesity treatment: a review of orlistat
}

This article was published in the following Dove Press journal:

ClinicoEconomics and Outcomes Research

2 July 2010

Number of times this article has been viewed

\section{Armineh Zohrabian \\ Division of Adult and Community Health, Centers for Disease Control and Prevention, Atlanta, GA, USA}

Correspondence:Armineh Zohrabian 4770 Buford Highway, NE, MS K-67, Atlanta, GA 3034I, USA

$\mathrm{Tel}+\mathrm{I} 7704885616$

Fax +I 7704885965

email abz8@cdc.gov

\begin{abstract}
The objective of this study was to review the current knowledge about the use of orlistat from clinical and economic perspectives, and to assess this drug's public health impact. Weight reduction by current antiobesity drugs, compared to placebo, is at most around $5 \mathrm{~kg}$. Orlistat, the most studied antiobesity drug, is associated with the least-severe adverse effects, but compared with other drugs in its class it also delivers the most modest weight loss versus placebo (less than $3 \mathrm{~kg}$ ). Orlistat appears to have a favorable risk/benefit profile, and cost-effectiveness ratios seem to be within a range that is generally considered acceptable. In the short-term, orlistat is related to reduced diabetes incidence and to slightly improved blood pressure and lipid profiles. Long-term clinical effects have been largely unstudied, however, and this study did not find reports that considered mortality as an endpoint. Given a very low continuation with orlistat treatment in the population and very modest and, apparently, only short-term clinical effects, orlistat is not likely to have a significant impact on the population health. Public health approaches of improving environmental and social factors to foster healthier food choices and increase physical activity remain essential for addressing the obesity epidemic.
\end{abstract}

Keywords: obesity, orlistat, weight loss, cost-effectiveness

\section{Introduction}

In most developed countries, obesity has become an epidemic of alarming proportions and a leading public health concern. Obesity is defined as a body mass index (BMI) of $30 \mathrm{~kg} / \mathrm{m}^{2}$ or greater. A BMI between 25 and $29.9 \mathrm{~kg} / \mathrm{m}^{2}$ is termed overweight. In the United States, overweight/obesity in children is defined as a BMI at or above the sex- and age-specific 95th percentile BMI cutoff points from the 2000 CDC Growth Charts (Centers for Disease Control and Prevention). ${ }^{1}$ Since 1980, obesity rates have more than doubled among US adults ${ }^{2}$ and tripled among US children. ${ }^{3}$ More than one third of US adults and $17 \%$ of US children are obese. ${ }^{2,3}$ In the last two decades, the prevalence of obesity has also almost doubled in Canada; currently, nearly $23 \%$ of adult Canadians are obese. ${ }^{4}$ Obesity is quickly rising in European countries as well; according to the most recent available data (covering 1997-2002), the prevalence for adults ranges from $6 \%$ (Norway) to 20\% (Hungary), and rates are highest in Central-Eastern Europe. ${ }^{5}$ Although the prevalence of obesity in China is relatively low compared with Western countries, it is the rapid increase of the condition, especially among children, that is particularly alarming. The prevalence of overweight and obesity in children aged 7-18 years increased 28 times and obesity increased four times between 1985 and 2000 in China. ${ }^{6}$ Data from the 2002 national nutrition and health survey showed that $14.7 \%$ of Chinese were overweight (BMI $\geq 25$ ) and another $2.6 \%$ 
were obese $(\mathrm{BMI} \geq 30)$. Since the Chinese population totals 1.3 billion, about one fifth of the one billion overweight or obese people in the world are Chinese. ${ }^{6}$ The World Health Organization estimates that by the year 2015, approximately 2.3 billion adults worldwide will be overweight, and more than 700 million will be obese. ${ }^{7}$

In the United States, obesity is a leading actual cause of death and is associated with many of the top 10 diseases with the highest mortality rates, including diabetes, heart disease, stroke, and cancer. ${ }^{8-10}$ It has psychological and social consequences, and is a risk factor for some respiratory diseases, such as sleep apnea and for many other conditions, such as complications during pregnancy. For these reasons, effective interventions to treat overweight and obesity are much needed, including those with only modest effects. Research has shown that even small losses in weight, such as 5\%-10\% of baseline weight, may have clinical importance, ${ }^{11,12}$ and may reduce blood pressure, glucose, cholesterol and triglycerides levels, ${ }^{13-15}$ potentially moderating cardiovascular diseases and diabetes. ${ }^{16-18}$

Obesity is currently responsible for $2 \%-8 \%$ of health costs and $10 \%-13 \%$ of deaths in some parts of Europe. ${ }^{7}$ In the United States, the annual medical burden of obesity increased from $6.5 \%$ of annual medical spending in 1998 to $9.1 \%$ in 2006 , possibly amounting to $\$ 147$ billion per year by $2008 .{ }^{19}$ Another question of concern is who bears the costs of obesity? A recent study showed that there may be a social welfare loss in a pooled-risk health insurance setting as a consequence of nonobese persons paying for medical treatment of obese persons. In the United States, this loss of social welfare, also known as external cost, was around $\$ 150$ per person. ${ }^{20}$

Pharmacological treatment of obesity has become widely-used in most countries, although the number of available drugs is still very limited. Two drugs, orlistat and sibutramine, are currently approved by the US Food and Drug Administration (FDA) and European Medical Agency (EMEA), and are available for the long-term treatment of obesity and overweight in the European Union and the United States. $^{21}$

Orlistat (tetrahydrolipstatin) is a lipase inhibitor that blocks about one-third of intestinal fat absorption. Biological research on orlistat started over 20 years ago. ${ }^{22}$ It has been in the drug market for a decade as a prescription medicine called Xenical (Roche, Basel, Switzerland), and more recently as an over-the-counter formulation called Alli (GlaxoSmithKline, Brentford, Middlesex, United Kingdom). The latter is sold in $60 \mathrm{mg}$ capsules, half the dosage of orlistat by prescription.
The objective of this study was to review the current knowledge about the use of orlistat from clinical and economic perspectives, as well as from a public health perspective.

\section{Methods}

Twelve databases, including Medline, Embase, PsycInfo, EconLit, CINAHL, Web of Science, Cochrane, ERIC, Health and Safety Science Abstracts, PILOTS, Social Services Abstracts, and Sociological Abstracts (CSA) were searched until August 2009. This search was intended to be as comprehensive as possible; however, this was not a systematic review. The search was limited to English language. Two different strategies were used. For the years before 2009, both indexed (keyword) and free-text terms were used with a boolean logic to establish relationships between the words orlistat and clinical treatment or cost or economic or effective. For the year 2009, we used only the term orlistat in our search without language restriction. After removing duplicates, a total of 712 articles were found. The references of identified papers were checked for related articles. Some individual articles may not be explicitly cited here if they were included in meta-analysis studies that are cited in this review.

\section{Clinical practice guidelines for orlistat}

Current clinical practice guidelines, ${ }^{23}$ set by the UK National Institute for Clinical Excellence in 2006, stipulate that orlistat treatment may be used in adults who meet one of the following criteria:

- A BMI of $30 \mathrm{~kg} / \mathrm{m}^{2}$ or more.

- A BMI of $28 \mathrm{~kg} / \mathrm{m}^{2}$ or more when associated risk factors, such as prediabetes, diabetes, hypertension, or cardiovascular diseases, are present. (Previous guidelines set the BMI at $27 \mathrm{~kg} / \mathrm{m}^{2}$ or more when obesity-associated conditions were present). ${ }^{24-26}$

For people of Asian heritage, the clinical guidelines from the American College of Physicians recommend lower thresholds for prescribing orlistat treatment: a BMI of 27.5 without comorbid conditions and 25 to 27.4 with comorbid conditions..$^{27}$

Orlistat should be prescribed only as part of an overall plan for managing obesity. ${ }^{24-28}$ Arrangements should be made for appropriate health professionals to offer information, support, and counseling on additional diet, physical activity, and behavioral strategies for losing weight, especially given that not all patients respond to a given obesity treatment drug. If a patient has not lost at least $2 \mathrm{~kg}$ after 
4 weeks of treatment, the patient is not likely to benefit from the drug. ${ }^{24}$ Therapy should be continued beyond 3 months only if the person has lost at least $5 \%$ of his or her initial body weight since starting drug treatment ${ }^{23}$ (or an average of 1 pound $\left\{0.45 \mathrm{~kg}\right.$ \} or more per week ${ }^{26}$ or $10 \%$ of weight over a 6-month period ${ }^{24}$ ). Rates of weight loss may be slower in people with type 2 diabetes, so less strict goals may be appropriate for this population. The decision to use drug treatment for longer than 12 months (usually for weight maintenance) should be made only after discussing potential benefits and limitations with the patient. The co-prescribing of orlistat with other drugs aimed at weight reduction is not recommended.

Recommendations for specific medications vary somewhat among guidelines. The American College of Physicians (ACP) argues that data are not sufficient to determine whether one drug is more efficacious than another when comparing sibutramine, orlistat, phentermine, diethylpropion, fluoxetine, and bupropion. ${ }^{27}$ In contrast, the Singapore Ministry of Health (SMOH) and the US Department of Veterans Affairs (VA), assert that the research evidence identifies orlistat and sibutramine as the drugs with the widest efficacy and safety data. ${ }^{28}$

With regard to duration of treatment, ACP asserts that data on long-term (>12 months) efficacy or safety are insufficient to inform the decision to continue treatment beyond 1 year. However, according to $\mathrm{SMOH}$ and VA guidelines, sibutramine and orlistat could be considered as a component of weight maintenance programs for up to 2 years and 4 years, respectively. ${ }^{28}$

\section{Weight loss}

Weight loss from pharmacotherapy is generally modest, ranging from $2 \mathrm{~kg}$ to $10 \mathrm{~kg}$. Weight is usually regained after discontinuation of the drug, and generally there is no difference between treatment and placebo groups several months after treatment ends. ${ }^{29,30}$ The longest orlistat study, Xenical in the Prevention of Diabetes in Obese Subjects (XENDOS), ${ }^{31}$ found statistically significant mean weight loss of $2.8 \mathrm{~kg}$ after 4 years' use of orlistat compared to lifestyle changes alone ( $5.8 \mathrm{~kg}$ vs $3 \mathrm{~kg}$ mean weight loss, respectively). The weight loss was similar between orlistat recipients with impaired glucose tolerance $(5.7 \mathrm{~kg})$ or normal glucose tolerance $(5.8 \mathrm{~kg})$ at baseline. This finding is consistent with the results of several meta-analyses that indicated the range of weight loss with orlistat use to be from $5.5 \mathrm{~kg}$ to $9.5 \mathrm{~kg} .{ }^{32-35}$ This weight loss is usually in the range of $5 \%-10 \%$ of a baseline weight. ${ }^{36}$
The main co-interventions in most weight loss studies were low-fat, low-energy diet and encouragement to exercise. For example, in the XENDOS study, all patients were prescribed a reduced-calorie diet (about $800 \mathrm{kcal} /$ day deficit) containing $30 \%$ of calories from fat and not more than $300 \mathrm{mg}$ of cholesterol per day. The prescribed energy intake was readjusted every 6 months to account for any weight lost during the preceding months. Patients were also encouraged to walk at least 1 extra kilometer a day in addition to their usual physical activity. All patients kept physical activity diaries. ${ }^{31}$ In a recent meta-analysis of longterm pharmacotherapy for obesity, all of the 16 randomized controlled trials (RCTs) of orlistat included low-fat, lowcalorie diet; 5 studies included exercise counseling; and 2 studies included exercise in addition to diet. ${ }^{33}$ Although the diet/exercise co-interventions were standardized within each individual study, the comparability across trials for these interventions is not clear.

The use of orlistat increased the absolute percentage of participants achieving 5\% and 10\% weight loss thresholds by $21 \%$ (pooled results of 14 RCTs) and 12\% (pooled results of 13 RCTs) respectively compared to placebo. ${ }^{33}$ Orlistat therapy increased the odds of attaining $\geq 5 \%$ weight loss compared to diet-only therapy after 1 year by an odds ratio (OR) of 2.54 (95\% confidence interval $[\mathrm{CI}]: 2.17-2.90)$ (pooled results of 10 RCTs), and after 2 years by an OR of 4.55 (95\% CI: 1.99-10.4) (pooled results of two RCTs). ${ }^{37}$

A meta-analysis of head-to-head studies comparing orlistat and sibutramine indicated that sibutramine was significantly more efficacious for achieving weight loss than orlistat, with the weighted mean difference in weight loss of $2.2 \mathrm{~kg}$ favoring sibutramine. ${ }^{32}$ However, sibutramine has more serious side-effects than orlistat.

The weight loss effects of orlistat on patients with diabetes were slightly lower than those without diabetes: placebo-subtracted weight loss was $2.3 \mathrm{~kg}$ (1.6 kg to $3 \mathrm{~kg}$; based on four studies) in patients with diabetes compared to $2.9 \mathrm{~kg}$ ( $2.5 \mathrm{~kg}$ to $3.2 \mathrm{~kg}$; based on 15 studies) in patients without diabetes. ${ }^{33}$ Persons with diabetes also seem to regain their weight more rapidly, although the mechanisms for this are unclear and the validity of this observation has not been systematically examined..$^{33,38,39}$

The effectiveness of orlistat or sibutramine on countering weight gain induced by antipsychotic drugs has not been studied yet. In individuals with established weight gain and metabolic issues, switching to an antipsychotic agent with lower weight gain potential and/or lifestyle modifications with physical activity are most effective in promoting weight loss. ${ }^{40}$ 


\section{Clinical considerations}

Modest weight loss in the obese of between 5\% and $10 \%$ of body weight is associated with improvements in cardiovascular risk profiles and reduced incidence of type 2 diabetes. ${ }^{12,35,41}$ However, treatment success, when defined as clinically meaningful weight loss that can be maintained for longer periods, has been limited. ${ }^{42-45}$ Furthermore, a majority of obese patients have multiple risk factors for cardiovascular diseases (CVD), including diabetes, prediabetes, hypertension, and dyslipidemia. The complex course of treatment for these conditions complicates behavioral change aimed at weight reduction. The clinical guidelines on obesity treatment state that the control of CVD should be given the same emphasis as weight-loss therapy because risk factors for CVD can be reduced whether or not weight loss efforts are successful. ${ }^{24}$

One empirical question is whether statistically-significant differences in weight loss observed between orlistat treatment and placebo have clinical significance. Findings of a recent meta-analysis suggested that weight loss of $\geq 5 \%$ was not consistently-associated with improvements in cardiovascular risk factors and appeared to be interventionspecific. ${ }^{37}$ Improvements were seen mainly in high-risk groups, because changes in risk factors were more likely in subjects with abnormal baseline levels. This was consistent with findings from observational studies that intentional weight loss was associated with increased longevity, but only in people with pre-existing disease. ${ }^{46,47}$

\section{Clinical effects in patients with type 2 diabetes mellitus}

Obese patients who have diabetes are considered to be at very high absolute risk for mortality. ${ }^{29}$ Their life expectancy may be shortened by as much as 15 years, with up to $75 \%$ dying of macrovascular complications..$^{48}$

Orlistat is shown to reduce the incidence of diabetes. ${ }^{31,33,49}$ Compared with lifestyle changes alone, adding orlistat changed the cumulative incidence of diabetes from $9 \%$ with placebo to $6.2 \%$ with orlistat, corresponding to a risk reduction of $37.3 \%(P=0.0032)$ over 4 years of treatment. ${ }^{31}$ The preventive effect was explained by differences in study participants with impaired glucose tolerance, among whom both lifestyle interventions and orlistat reduced the rate of progression to type 2 diabetes mellitus.$^{49}$ However, lifestyle interventions seemed to be at least as effective as orlistat: the pooled hazard ratios were 0.51 (95\% CI: 0.44 to 0.60 ) for lifestyle interventions versus standard advice, and 0.44 (95\% CI: 0.28 to 0.69 ) for orlistat versus the control group.
A large meta-analysis of orlistat with a total of 2036 participants and follow-up periods of between 24 and 57 weeks indicated that the pooled reduction for glycosylated hemoglobin was $0.5 \%$ (95\% CI: 0.3 to 0.6$) ;{ }^{29}$ previous research has shown that $1 \%$ absolute reductions in glycosylated hemoglobin lead to significant reductions in microvascular complications from diabetes. ${ }^{50,51}$ In the meta-analysis, the pooled reduction for fasting glucose was $0.8 \mathrm{mmol} / \mathrm{L}(95 \% \mathrm{CI}:-1.1,-0.5) .{ }^{29}$ Another meta-analysis ${ }^{37}$ found that orlistat had inconsistent effects on glycemic control: modest but significantly greater reductions in fasting blood glucose $(0.1-1.7 \mathrm{mmol} / \mathrm{L})$ than diet-only therapy in six studies, but no difference in two studies. The greatest improvements in glycemic control occurred in subjects with type 2 diabetes mellitus..$^{52,53}$

The pooled effects of orlistat treatment in patients with diabetes were as follows: total cholesterol, $-0.4 \mathrm{mmol} / \mathrm{L}$ (95\% CI: $-0.5,-0.3)$; LDL cholesterol, $-0.3 \mathrm{mmol} / \mathrm{L}$ (95\% CI: $-0.4,-0.2)$; triglycerides, $-0.2 \mathrm{mmol} / \mathrm{L}(95 \% \mathrm{CI}:-0.4$, $-0.1)$; systolic blood pressure (SBP), $-3.0 \mathrm{mmHg}(95 \%$ CI: $-6.3,0.3$ ); diastolic blood pressure (DBP), $-4.2 \mathrm{mmHg}$ (95\% CI: $-7.8,-0.6){ }^{29}$ It remains unclear whether improved glycemic control and lipid levels associated with orlistat use can be maintained over the long-term to influence the risk of complications.

\section{Clinical effects on cardiovascular risk factors}

International studies have shown that differences in serum cholesterol concentration and dietary saturated fat are the most important determinants of the differences in mortality from ischemic heart disease between countries, accounting for over $80 \%$ of the total variation. ${ }^{54}$ When assessing the significance and effect of orlistat on cholesterol, several issues have to be considered. First, studies suggest that there is no threshold below which a lower serum cholesterol concentration is not associated with a lower risk of ischemic heart disease; and second, an individual person may have difficulty in lowering serum cholesterol concentration through dietary change by more than about $0.3 \mathrm{mmol} / \mathrm{L}$. However, it is also well documented that at community levels a reduction of $0.6 \mathrm{mmol} / \mathrm{L}$ (about $10 \%$ ) in serum concentrations of total and low density lipoprotein cholesterol is feasible and has occurred through dietary change over periods of a few years. ${ }^{54}$ This level of reduction is associated with a decrease in the risk of ischemic heart disease of about $50 \%$ at the age of 40 years, $40 \%$ at 50 years, $30 \%$ at 60 years, and $20 \%$ at 70 years and over. ${ }^{54}$ 
Finally, a very important consideration is that in the first two years after lowering cholesterol little reduction in risk of ischemic heart disease occurs, and the full reduction in risk of ischemic heart disease is achieved within five years. ${ }^{54}$

Obesity-associated hypertension is especially difficult to treat and puts patients at a substantially increased risk for cardiovascular events. ${ }^{55}$ Weight reduction is recommended in major guidelines as the first step in treating hypertension. ${ }^{56}$ However, long-term weight reduction, which is necessary to sustain blood pressure control, may not be feasible in the majority of patients. ${ }^{57}$ While pharmacological weightreducing interventions with orlistat may lead to reduction in blood pressure as well as weight,,$^{33,58}$ additional studies are needed to determine the long-term ( $>1$ year) efficacy and safety of antihypertensive and antiobesity management strategies in overweight and obese hypertensive patients.

A meta-analysis of the effect of weight-reducing interventions in hypertensive patients indicated that both diet-based interventions and orlistat reduced blood pressure, but diets led to greater reductions than orlistat ${ }^{58}$ (diet: SBP weighted mean difference [WMD], $-6.3 \mathrm{mmHg}$; DBP WMD, $-3.4 \mathrm{mmHg}$; orlistat: SBP WMD, $-2.5 \mathrm{mmHg}$; DBP WMD, $-2.0 \mathrm{mmHg}$; sibutramine: SBP WMD $+3.2 \mathrm{mmHg}$ ). An earlier meta-analysis ${ }^{37}$ found that orlistat had no significant effect on blood pressure compared with dietary/lifestyle-only therapy, except in two out of nine studies that measured blood pressure, one of which involved subjects with poorly controlled hypertension. ${ }^{59}$

Based on results from 11 RCTs, orlistat therapy was associated with significantly-greater reductions in LDL levels $(0.11-0.38 \mathrm{mmol} / \mathrm{L})$ than diet-only therapy, but in most studies there were no significant effects on HDL and triglyceride levels. ${ }^{37}$ Mannucci and colleagues ${ }^{59}$ found that orlistat affected serum lipid profiles in overweight and obese subjects, independently of weight loss. In the 15 trials with orlistat, mean weight loss showed a significant correlation with mean reduction of total cholesterol $(\mathrm{r}=0.48$; $P<0.05$ ), which maintained statistical significance after adjustment for mean weight loss $(\mathrm{B}=-2.81 \pm 1.28$; $P<0.05)$. However, a randomized control study of 180 Asian patients indicated no significant reductions in total cholesterol, LDL, HDL and triglyceride levels after 1 year of treatment. ${ }^{60}$ Another study of Chinese patients indicated that although there were significant short-term reductions in total cholesterol and LDL levels which resulted from a 24-week treatment with orlistat, 12 weeks after discontinuing the treatment these reductions were no longer significant. ${ }^{61}$
A recent RCT investigated the effect of long-term (3.2 year) weight loss on serum levels of the nontraditional cardiovascular risk factors interleukin (IL)-18 and matrix metalloproteinase (MMP)-9. It found that orlistat treatment had no independent effects on IL-18, MMP-9, or leptin. However, decreases in IL-18 were associated with changes in body mass index independent of changes in blood pressure and lipids, indicating that even a minor weight reduction $(>5 \%)$ has beneficial effects on these nontraditional cardiovascular risk markers. ${ }^{62}$

No studies were found that assessed the association of orlistat on all-cause or specific-cause mortality. Research findings on the association between any type of intentional weight loss and mortality are mixed. ${ }^{15,46,47,63-66} \mathrm{~A}$ prospective cohort study which used a probability sample of the US population found that self-reported intention to lose weight was associated with lower all-cause mortality, independent of weight change, perhaps because weight loss attempts were a marker of other healthy behaviors. ${ }^{67}$

\section{Weight regain}

The majority of obese patients regain most of the weight initially lost in successful interventions, ${ }^{29,30}$ regardless of orlistat use. ${ }^{68}$ In nondiabetic populations, comprehensive, intensive group behavioral programs without pharmacotherapy produced mean losses of $8 \mathrm{~kg}$ to $10 \mathrm{~kg}$ at six months, with a regain of $30 \%$ to $35 \%$ of weight loss at one year, and $50 \%$ of participants returned to baseline weight by 3 to 5 years. ${ }^{43,45} \mathrm{~A}$ recent meta-analysis of RCTs of long-term pharmacotherapy showed that participants in both orlistat and placebo arms showed similar amounts of weight regain, though the weight differential observed after the weight-loss phase was preserved. ${ }^{33}$

Weight regain was studied in a 3-year Scandinavian multicenter RCT of obese patients with metabolic risk factors such as dyslipidemia, impaired fasting glucose, and diet-treated type 2 diabetes. ${ }^{42}$ Initially an 8 -week very-low-energy diet induced weight loss of $14.4 \pm 2 \mathrm{~kg}$. Those who lost $\geq 5 \%$ of their body weight (309 of 383) were then randomized to receive lifestyle counseling for 3 years together with either orlistat $120 \mathrm{mg}$ three times a day or matching placebo capsules. The addition of orlistat was associated with maintenance of an extra $2.4 \mathrm{~kg}$ weight loss for up to 3 years. However, a subsequent retrospective study revealed that the use of orlistat compared with placebo in a subgroup of the Scandinavian study population did not appear to influence dietary intake at 1 year. ${ }^{69}$ Furthermore, subjects who chose to continue taking orlistat two months after the end of the 3-year trial had higher dietary intake of 
fat compared to subjects not taking orlistat. Perhaps this was a case of moral hazard, where patients counted on orlistat to compensate for increased fat consumption and not complying with dietary recommendations. This suggests that orlistat is not useful as a self-control device (via adverse side-effects to motivate patients to comply with dietary recommendations see below) if side-effects subside after long-term use.

\section{Adverse effects and discontinuation}

The use of orlistat has been associated with several mild-to-moderate gastrointestinal adverse effects, such as oily stools, diarrhea, abdominal pain, and fecal spotting, which generally decrease in frequency with ongoing orlistat treatment. The risk-benefit balance may be affected by the duration of drug use: cardiovascular benefits are expected only after long-term use, whereas the adverse effects tend to occur at the beginning of treatment. Another side effect is that orlistat interferes with the absorption of fat-soluble vitamins, as well as many drugs (such as warfarin, amiodarone, ciclosporin and thyroxine), affecting their bioavailability and effectiveness. More serious but less common conditions associated with the liver have been reported, such as cholelithiasis, cholostatic hepatitis and subacute liver failure, as well as acute kidney injury and crystal nephropathy. ${ }^{70,71}$

A recent population-based cohort study in the Netherlands found that both cardiovascular and psychiatric comorbidities were more prevalent among patients starting antiobesity drug treatment, including orlistat, compared to nonstarters. This increased prevalence of comorbidities constitutes a baseline risk which may translate in higher occurrence of psychiatric and cardiovascular diseases during the use of the drugs, independent of the drugs. In this study, $77.7 \%$ of the patients stopped using antiobesity drugs within 90 days. ${ }^{72}$ This rate is higher than the discontinuation rate reported by prescription-event monitoring studies on orlistat in the UK, ${ }^{73}$ where $30.3 \%$ of users of orlistat stopped the use in 3 months. The nonreimbursement status of the antiobesity drugs in the Netherlands may have contributed to this difference.

In the 4-year XENDOS RCT study, 52\% of orlistat-treated patients completed treatment compared with $34 \%$ of placebo recipients. ${ }^{32}$ Higher attrition in the placebo group was perhaps because control participants became unblinded due to fewer gastrointestinal adverse events and had weight loss expectations that were not being fulfilled. ${ }^{30,74}$ The persistence rates in the general population, outside the RCT setting, are even poorer. A recent study created an inception cohort of nearly 17,000 orlistat users, based on population-based administrative data.
The observed one-year persistence rates were $<10 \%$, and the 2 -year persistence rates were only $2 \%{ }^{75}$

Attrition has an impact on evaluation of the drug's effectiveness. Last outcome-carried-forward data may have variable effects on measured outcomes, depending on when the participant dropped out. If drug treatment was effective and the participant dropped out early after achieving minimal weight loss, final outcomes would be biased toward the null effect. If participants dropped out after 4 to 6 months in the longer follow-up studies, however, their departure weight might have been lower than it would have been had they completed the study, as weight loss with pharmacotherapy tends to plateau at 6 months. ${ }^{30}$

\section{Use of orlistat in clinical practice}

There is limited population-based data on diet, physical activity behaviors, and weight loss among users of prescription weight loss medications. The best results with orlistat seem to be obtained when it is combined with an intensive group program of lifestyle modification. ${ }^{76-78}$ An analysis of data from the 1998 US Behavioral Risk Factor Surveillance System found that $10.2 \%$ of obese women and $3.1 \%$ of obese men reported using prescription weight loss medications in the past 2 years. Among current prescription weight loss medication users, only $26.7 \%$ reported both eating fewer calories and meeting recommended leisure-time physical activity. Of those meeting both recommendations, almost half $(47.2 \%)$ had lost $10 \%$ of their pretreatment body weight. Of current users, $9 \%$ reported using the medications for weight maintenance. ${ }^{78}$

Physicians' training and attitudes with regard to obesity treatment have recently been studied. ${ }^{78,79}$ Physicians see an estimated $25 \%$ of the US population every month ${ }^{80}$ and overweight and obese patients represent approximately $60 \%$ of this patient population. ${ }^{81}$ However, only $56 \%$ of surveyed physicians felt qualified to treat obesity, $46 \%$ felt successful in this realm, more than $40 \%$ had a negative reaction towards the appearance of obese patients, and 18\% felt uncomfortable when examining an obese patient. ${ }^{79}$ Patients who reported receiving physician counseling about weight loss were up to two times more likely to report that they were currently trying to lose weight. ${ }^{82,83}$ Based on a 2006 survey of 256 patients, ${ }^{84}$ only $65 \%$ of obese patients reported receiving advice to lose weight, while according to the 1996 survey of the Behavioral Risk Factor Surveillance System, less than half of obese patients reported that their health care professional advised them to lose weight. ${ }^{82,83}$ In a recent physicians' survey, however, the majority of physicians $(75.5 \%)$ 
reported 'always' or 'nearly always' addressing weight control issues with their overweight and obese patients. ${ }^{85}$ This may indicate miscommunication among physicians and patients, although it appears that over the years the number of physicians who advise patients to lose weight has increased. The most common recommended weight-control strategies were increasing physical activity, reducing consumption of fast foods, reducing portion sizes, and reducing soda consumption. Weight loss medications were rarely advised. Consistent with an earlier study, ${ }^{86}$ physicians reported high expectations for weight loss among their obese patients, with a $21.5 \%$ weight loss being 'acceptable' and a $10.6 \%$ weight loss, 'disappointing'. ${ }^{85}$ These high expectations are consistent with and may, in part, reflect most patients' notoriously high weight loss expectations. ${ }^{87,88}$ Nonetheless, these findings are surprising in light of the scientific consensus that as little as a $5 \%$ to $10 \%$ weight loss is associated with significant health benefits. ${ }^{24}$

Realizing the importance of physician training, GlaxoSmithKline (GSK) partnered with the American Dietetic Association and the American Pharmaceutical Association on education programs for doctors when launching the over-the counter version of orlistat, Alli (GSK, Brentford, Middlesex, United Kingdom). GSK presented the diet drug less as a pill than a lifestyle, and claimed that up to $50 \%$ greater weight reduction would be possible compared to diet and exercise alone, but only if people undergoing treatment with Alli stick to a strict regimen of diet and exercise as well. ${ }^{89}$

\section{Economic considerations}

The economic approach stresses that health promotion outcomes are determined in part by the forces of consumer demand and producer supply. Consumer demand for health-related goods inevitably involves tradeoffs between health and other desirables. For example, to purchase medication, consumers spend money that could have been used to buy other goods and services. To exercise, consumers may have to give up time spent in sedentary leisure activity.

The supply side of health promotion includes providers of health-related goods and services, the pharmaceutical industry, healthcare providers, and health insurers. Developments in these markets have been the result of the interplay between producers and regulators. As long as market mechanisms and enforcement of deceptive advertising laws sufficiently discourage deceptive claims, the pressures created by competition should push produc- ers to improve their products in dimensions that consumers value, and improve the information environment in which consumers make product choices. ${ }^{90}$ However, advertisements of orlistat generally associate its use with losing several dress sizes, contributing to unrealistic expectations. Many consumers who start using orlistat soon discontinue its use generally because of unmet weight loss expectations and side effects.

Another economic aspect of orlistat use is the question of who bears the costs associated with treatment. Reimbursement of drug charges may impact consumers' demand for obesity treatments. While the costs of lifestyle changes are fully covered by the obese person, in terms of time spent on physical activity or disutility of dieting, the costs of drugs become lower to the obese person when they are covered by insurance. This may change an obese person's preference in favor of drug treatment.

\section{Cost-effectiveness of orlistat}

The incremental cost-effectiveness of orlistat has been assessed in many countries, including Italy, the Netherlands, Sweden, the United Kingdom, and the United States. A recent systematic review and meta-analysis of economic evaluations of weight loss drug treatments included 14 articles, of which 9 were on orlistat. ${ }^{91}$ Physical activity was considered only in 2 studies, in the United States ${ }^{92}$ and Italy, ${ }^{93}$ as part of the comparator lifestyle modification (diet plus physical activity). Time horizons varied from the treatment period only (1-4 years) to 80 years. Recent studies had longer time horizons and modeled effects of long-term sequelae, whereas the time horizons of early studies included only the treatment years. Longer studies modeled effects on diabetes, micro- and macrovascular complications, coronary heart disease, and death. The median incremental cost-effectiveness ratio was 16,000 euros per quality-adjusted life year (QALY) (range, 10,000-88,000), with the worst cost-effectiveness occurring when recommended stop rules for nonresponding patients were not applied. All studies but three were funded by the manufacturing company, and the median incremental costeffectiveness ratio was considerably higher for independent than for sponsored analyses (62,000 euros vs 15,000 euros/ QALY). However, two of the three independent cost utility analyses did not use recommended stop rules, as compared with one of eight manufacturer-sponsored analyses. Although most of the reported incremental cost-effectiveness ratios for orlistat seemed to be within acceptable range, some studies recommended low-calorie diets ${ }^{94}$ or varying combinations of 
diet, physical activity, and behavior modification ${ }^{95}$ as better options for combating obesity.

The results of cost-effectiveness analyses were most sensitive to assumptions regarding weight loss sustainability and utility per kilogram lost. ${ }^{91}$ Restricting orlistat treatment to specific groups and the cost of doctor's visits were also important. Foxcroft ${ }^{96}$ compared the cost-utility of orlistat treatment under two treatment criteria: 1) criteria from recent guidance from the UK National Institute for Clinical Excellence (NICE), which recommended stopping treatment if weight loss was less than $5 \%$ at Month 3 , and less than $10 \%$ at Month 6; and 2) criteria from the European Agency for the Evaluation of Medicinal Products (EMEA) license for orlistat prescription in the European community which recommended stopping treatment if weight loss was less than $5 \%$ at 3 months. The costs per QALY gained for the EMEA criteria were $£ 19,005$ compared to $£ 24,431$ when NICE criteria were applied. Both of these results were better than a previous estimate of $£ 45,881$ per QALY, ${ }^{97}$ reflecting the more restrictive criteria for the continued use of orlistat, as well as taking into account that prescriptions were almost always provided by general practitioners rather than more expensive hospital specialists. The finding that EMEA criteria resulted in a more favorable estimate indicated that the NICE criteria may have narrowed the treatment population too far. ${ }^{96}$

No study was available on cost-effectiveness of Alli. Given that the Alli dosage is only half of the prescription-strength orlistat dosage (60 mg vs $120 \mathrm{mg}$ ), its cost-effectiveness may be less favorable because of lower effectiveness. On the other hand, because Alli is not a prescription drug, the overall cost of treatment by Alli is lower, which will improve its cost-effectiveness.

\section{Use of orlistat in children and adolescents}

Overweight in adolescence is associated with increased early all-cause and coronary heart disease mortality rates in adult men and increased risks for coronary heart disease and atherosclerosis in both adult men and adult women. ${ }^{98-103}$

In 2003, orlistat was approved for use in 12-18 year old adolescents in the United States and later in the European Union. In children younger than 12 years, drug treatment may be used only in exceptional circumstances, if severe life-threatening comorbidities (such as sleep apnea or raised intracranial pressure) are present, ${ }^{23}$ and only if a formal program of intensive lifestyle modification has failed. In general, children with a BMI below the 95 th percentile should not be treated with antiobesity drugs. ${ }^{104}$
Several limitations discourage physicians from early implementation of drug therapies: 1) the limited and inconclusive nature of data supporting the use of pharmacological therapy for pediatric overweight, especially that long-term effects are unknown; ${ }^{105,106} 2$ ) reduced efficacy of antiobesity drugs over time, with a plateau after 6 months of treatment, an effect also noted with hypocaloric diets; ${ }^{101} 3$ ) the complexity of weighing the relative risk of severe adverse events in children against the long-term potential for obesity-related morbidity and mortality; and 4) the likelihood that drug therapy will have higher lifetime risks and costs than behavioral interventions.

A recent meta-analysis of treatment of pediatric obesity showed that orlistat was associated with a significant fall in BMI of $0.7 \mathrm{~kg} / \mathrm{m}^{2}$, but treatment was associated with increased rates of gastrointestinal side effects, including abdominal discomfort, pain, and steatorrhea. ${ }^{107,108}$ Side effects were usually mild to moderate and generally decreased in frequency with continued treatment. A major concern, especially for growing adolescents, is the potential decrease in absorption of fat soluble vitamins. Finally, orlistat must be taken with each meal, thus reducing its utility in children because they are often in school during lunchtime. ${ }^{108}$

Children with psychiatric illness are at greater risk for obesity than those in the general population. In part, this greater risk is due to the escalating use of psychotropic medications. ${ }^{109}$ Because there are only limited intervention studies available for obese children with psychiatric illnesses, general childhood obesity studies should be referenced for trials in this population.

\section{Discussion and concluding comments}

Antiobesity drugs are commonly used population-wide and they generate hundreds of million dollars in annual sales. Weight reduction by current antiobesity drugs compared to placebo is at most around $5 \mathrm{~kg}$. The drug orlistat is associated with the least-severe adverse effects, but compared with other drugs in its class it also delivers the most modest weight loss versus placebo (less than $3 \mathrm{~kg}$ ). ${ }^{31-33,110}$

In general, orlistat appears to have a favorable risk/benefit profile, and most of the estimated cost-effectiveness ratios seem to be within the range that is generally considered acceptable. In the short term, orlistat is associated with lower diabetes incidence and slightly improved blood pressure and lipid profiles. It has also been found to have a beneficial effect on nonalcoholic fatty liver disease. ${ }^{70}$ 
Questions remain regarding whether improvements in risk factors may occur in all obese persons or only in high-risk groups, whether orlistat affects general morbidity and mortality in treated populations, and whether weight loss studies are applicable to the everyday clinical management of obese patients. Few studies on orlistat have had longer than 3 years of follow-up, whereas studies of hypertension or diabetes management typically have 4-8 years of follow-up to assess potential improvements in cardiovascular outcomes. ${ }^{111}$ Losses to follow-up were typically $30 \%-60 \%$, whereas less than $20 \%$ loss to follow-up is a minimum requirement for clinical trials. Gastrointestinal side effects also limit the applicability of the results in clinical practice. Therapy is regarded as a long-term necessity because weight regain invariably follows drug discontinuation. ${ }^{29,30}$ However, weight loss plateau and weight regain occur even when orlistat treatment was continued beyond one year. ${ }^{68}$

Given the very low continuation with orlistat treatment in the population - less than $10 \%$ the first year and only $2 \%$ in the second year ${ }^{75}$ - orlistat may not have a significant impact on the obesity epidemic. Sibutramine, the other drug approved both in the United States and Europe, is slightly more effective but has more serious side effects. The new generation of antiobesity drugs will not be available in the near future. Some hope exists for miracle drugs, such as the recent discovery of the 'exercise pill' known as AICAR (5-aminoimidazole-4-carboxamide-1- $\beta$-D-ribofuranoside); however, no pharmaceutical agent with a single molecular target will be able to produce all the beneficial effects that physical activity can: exercise has multisystem effects. ${ }^{12,113}$ In 2008 several community-based physical activity interventions were shown to offer good value for money, with costeffectiveness ratios ranging between $\$ 14,000$ and $\$ 69,000$ US dollars per QALY gained. ${ }^{114}$

Educating physicians and patients about health benefits of even modest weight loss may improve population-wide continuation with antiobesity treatment, including the appropriate use of orlistat in conjunction with diet and physical activity. In addition, improving environmental and social factors and establishing community programs that promote healthy lifestyles remain essential to fostering healthier food choices and increasing physical activity.

\section{Disclosure}

The findings and conclusions in this report are those of the author and do not necessarily represent the views of the Centers for Disease Control and Prevention. Use of trade names is for identification only and does not imply endorsement by the US Department of Health and Human Services.

\section{References}

1. Kuczmarski RJ, Ogden CL, Guo SS, et al. 2000 CDC growth charts for the United States: methods and development. Vital Health Stat 11. 2002;1-190. 2.

2. US National Center for Health Statistics. Table 75: Overweight, obesity, and healthy weight among persons 20 years of age and over, by selected characteristics: 1960-1962 through 2003-2006. In: Health, United States, 2008. Hyattsville, MD: US Department of Health and Human Services; 2009.

3. US National Center for Health Statistics. Table 76: Overweight among children and adolescents 6-19 years of age, by selected characteristics: 1963-1965 through 2003-2006. In: Health, United States, 2008. Hyattsville, MD: US Department of Health and Human Services; 2009.

4. Tjepkema M. Adult Obesity in Canada: measured height and weight (Report No. 82-620-MWE.) Ottawa: Statistics Canada; 2005.

5. Rabin BA, Boehmer TK, Brownson RC. Cross-national comparison of environmental and policy correlates of obesity in Europe. Eur J Public Health. 2007;17:53-61.

6. Wu Y. Overweight and obesity in China. BMJ. 2006;333:362-363.

7. WHO/Europe. The challenge of obesity in the WHO European Region. Fact Sheet Euro/13/05. Copenhagen, Bucharest, 2005 Sep 12. Available at: http://www.euro.who.int/document/mediacentre/fs1305e.pdf. Accessed July 2009.

8. Mokdad AH, Marks JS, Stroup DF, Gerberding JL. Actual causes of death in the United States, 2000. JAMA. 2004;291:1238-1245.

9. Mokdad AH, Marks JS, Stroup DF, Geberding JL. Correction: Actual causes of death in the United States, 2000. JAMA. 2005;293: 293-294.

10. McGinnis JM, Foege WH. Actual causes of death in the United States. JAMA. 1993;270:2207-2212.

11. Blackburn G. Effect of degree of weight loss on health benefits. Obes Res. 1995;3 Suppl 2:S211-S216.

12. Goldstein DJ. Beneficial effects of modest weight loss. Int J Obes Relat Metab Disord. 1992;16:397-415.

13. Dattilo AM, Kris-Etherton PM. Effects of weight reduction on blood lipids and lipoproteins: a meta-analysis. Am J Clin Nutr. 1992;56:320-328.

14. Wing R, Jeffery RW. Effect of modest weight loss on changes in cardiovascular risk factors: are there differences between men and women or between weight loss and maintenance? Int J Obes Relat Metab Disord. 1995; 19:67-73.

15. Williamson DF, Thompson TJ, Thun M, Flanders D, Pamuk E, Byers T. Intentional weight loss and mortality among overweight individuals with diabetes. Diabetes Care. 2000;23:1499-1504.

16. Anderson JW, Konz EC. Obesity and disease management: effects of weight loss on comorbid conditions. Obes Res. 2001;9 Suppl 4: S326-S334.

17. Singh RB, Rastogi SS, Verma R, et al. Randomized controlled trial of cardioprotective diet in patients with recent acute myocardial infarction: results of one year follow-up. BMJ. 1992;304:1015-1019.

18. Glazer G. Long-term pharmacotherapy of obesity 2000. A review of efficacy and safety. Arch Intern Med. 2001;161:1814-1824.

19. Finkelstein EA, Trogdon JG, Cohen JW, Dietz W. Annual medical spending attributable to obesity: payer-and service-specific estimates. Health Affairs. 2009;28:w822-w831.

20. Bhattacharya J, Sood N. Health insurance and the obesity externality. National Bureau of Economic Research Working Paper (No. 11529). Cambridge, MA: National Bureau of Economic Research; 2005. Available at: http://www.nber.org/papers/w11529. Accessed May 2009

21. Idelevich E, Kirch W, Schindler C. Current pharmacotherapeutic concepts for the treatment of obesity in adults. Ther Adv Cardiovasc Dis. 2009;3:75-90

22. Hartmann D, Hussain Y, Guzelhan C, Odink J. Effect on dietary fat absorption of orlistat, administered at different times relative to meal intake. Br J Clin Pharmac. 1993;36:266-270. 
23. UK National Institute for Health and Clinical Excellence. Obesity: Guidance on the Prevention, Identification, Assessment And Management Of Overweight And Obesity In Adults And Children. London: December 2006. Available at http://www.nice.org.uk/CG043. Accessed September 2009.

24. US National Heart, Lung, And Blood Institute Obesity Education Initiative Expert Panel. Clinical guidelines on the identification, evaluation, and treatment of overweight and obesity in adults: the evidence report. Obes Res. 1998;6:S51-S209.

25. Singapore Ministry of Health. Obesity. Singapore: Singapore Ministry of Health; April 2004.

26. US Department of Veterans Affairs, Department of Defense (VA/DoD). VA/DoD Clinical Practice Guideline for Screening and Management of Overweight and Obesity. Washington D.C.: US Department of Veterans Affairs, Department of Defense; 2006.

27. American College of Physicians (ACP). Pharmacologic and surgical management of obesity in primary care: a clinical practice guideline from the American College of Physicians. Ann Intern Med. 2005; 142:525-531.

28. US National Guideline Clearinghouse. Guideline synthesis: assessment and treatment of obesity and overweight in adults. In: National Guideline Clearinghouse [website]. Rockville (MD): 2005 Apr 18 (revised 2009 Jan). Available at http://www.guideline.gov. Accessed September 2009.

29. Norris SL, Zhang X, Avenell A, Gregg E, Schmid CH, Lau J. Pharmacotherapy for weight loss in adults with type 2 diabetes mellitus. Cochrane Database of Systematic Reviews 2005, Issue 1. Art. No.: CD004096. DOI:10.1002/14651858.CD004096.pub2.

30. US National Task Force on the Prevention and Treatment of Obesity. Long-term pharmacotherapy in the management of obesity. JAMA. 1996;276:1907-1915.

31. Torgerson JS, Hauptman J, Boldrin MN, Sjöström L. XENICAL in the prevention of diabetes in obese subjects (XENDOS) study: a randomized study of orlistat as an adjunct to lifestyle changes for the prevention of type 2 diabetes in obese patients. Diabetes Care. 2004;27:155-161.

32. Neovius M, Johansson K, Rossner S. Head-to-head studies evaluating efficacy of pharmaco-therapy for obesity: a systematic review and meta-analysis. Obes Rev. 2008;9:420-427.

33. Rucker D, Padwal R, Li SK, Curioni C, Lau DCW. Long-term pharmacotherapy for obesity and overweight: updated meta-analysis. Br Med J. 2007;335:1194-1199.

34. Li ZP, Maglione M, Tu W, et al. Meta-analysis: pharmacologic treatment of obesity. Ann Intern Med. 2005;142:532-546.

35. Avenell A, Broom J, Brown TJ, et al. Systematic review of the long-term effects and economic consequences of treatments for obesity and implications for health improvement. Health Technol Assess. 2004;8:iii-182.

36. Coutinho W. The first decade of sibutramine and orlistat: a reappraisal of their expanding roles in the treatment of obesity and associated conditions. Arq Bras Endocrinol Metab. 2009;53:262-270.

37. Douketis JD, Macie C, Thabane L, Willamson DF. Systematic review of long-term weight loss studies in obese adults: clinical significance and applicability to clinical practice. Int J Obes. 2005;29: $1153-1167$.

38. Wing RR. Weight loss in the management of type 2 diabetes. In: Gerstein HC, Haynes RB, editors. Evidence-Based Diabetes Care. Ontario, Canada: B.C. Decker, Inc; 2000:252-276.

39. Greenway F, Heber D, Raum W, Morales S. Double-blind, randomized, placebo-controlled clinical trials with non-prescription medications for the treatment of obesity. Obes Res. 1999;7:370-378.

40. Rege S. Antipsychotic-induced weight gain in schizophrenia: mechanisms and management. Aust N Z J Psychiatry. 2008;42:369-381.

41. Padwal RS, Majumdar SR. Drug treatments for obesity: orlistat, sibutramine, and rimonabant. Lancet. 2007;369:71-77.

42. Richelsen B, Tonstad S, Rossner S, et al. Effect of orlistat on weight regain and cardiovascular risk factors following a very-low-energy diet in abdominally obese patients: a 3-year randomized, placebo-controlled study. Diabetes Care. 2007;30:27-32.
43. Kramer FM, Jeffery RW, Forster JL, Snell MK. Long-term follow-up of behavioral treatment for obesity: patterns of weight regain among men and women. Int J Obes. 1989;13:123-136.

44. Ayyad C, Andersen T. Long-term efficacy of dietary treatment of obesity: a systematic review of studies published between 1931 and 1999. Obes Rev. 2000;1:113-119.

45. Wadden TA, Butryn ML, Byrne KJ. Efficacy of lifestyle modification for long-term weight control. Obes Res. 2004;12(Suppl):S151-S162.

46. Williamson DF, Pamuk E, Thun M, Flanders D, Byers T, Heath C. Prospective study of intentional weight loss and mortality in never-smoking overweight US white women aged 40-64 years. Am J Epidemiol. 1995;141:1128-1141.

47. Williamson DF, Pamuk E, Thun M, Flanders D, Byers T, Heath C. Prospective study of intentional weight loss and mortality in overweight white men aged 40-64 years. Am J Epidemiol. 1999;149: 491-503.

48. Davies MJ, Tringham JR, Troughton J, Khunti KK. Prevention of type 2 diabetes mellitus. A review of the evidence and its application in a UK setting. Diabet Med. 2004;21:403-414.

49. Gillies CL, Abrams KR, Lambert PC, et al. Pharmacological and lifestyle interventions to prevent or delay type 2 diabetes in people with impaired glucose tolerance: Systematic review and meta-analysis. $B M J$. 2007;334:299

50. UK Prospective Diabetes Study Group. Intensive blood glucose control with sulphonylureas or insulin compared with conventional treatment and risk of complications in patients with type 2 diabetes. Lancet. 1998;352:837-853.

51. The Diabetes Control and Complications Trial Research Group. The effect of intensive treatment of diabetes on the development and progression of long-term complications in insulin-dependent diabetes mellitus. New Engl J Med. 1993;329:977-986.

52. Kelley DE, Bray GA, Pi-Sunyer FX, et al. Clinical efficacy of orlistat therapy in overweight and obese patients with insulin-treated type 2 diabetes: A 1-year randomized controlled trial. Diabetes Care. 1998;25:1033-1041.

53. Miles JM, Leiter L, Hollander P, et al. Effect of orlistat in overweight and obese patients with type 2 diabetes treated with metformin. Diabetes Care. 2002;25:1123-1128.

54. Law MR, Walk NJ, Thompson SG. By how much and how quickly does reduction in serum cholesterol concentration lower risk of ischaemic heart disease? BMJ. 1994;308:367-372.

55. Sharma AM, Bramlage P, Kirch W. Antihypertensive effect of irbesartan and predictors of response in obesity-associated hypertension: a prospective, open-label study. Clin Drug Investig. 2005;25:765-776.

56. Siebenhofer A, Horvath K, Jeitler K, et al. Long-term effects of weightreducing drugs in hypertensive patients. Cochrane Library Issue 2; 2009. Available at http://www.thecochranelibrary.com. Accessed September 2009.

57. Douketis JD, Sharma AM. The management of hypertension in the overweight and obese patient - is weight reduction sufficient? Drugs. 2004;64:795-803.

58. Horvath K, Jeitler K, Siering U, et al. Long-term effects of weightreducing interventions in hypertensive patients: Systematic review and meta-analysis. Arch Intern Med. 2008;168:571-580.

59. Mannucci E, Dicembrini I, Rotella F, Rotella CM. Orlistat and sibutramine beyond weight loss. Nutr Metab Cardiovasc Dis. 2008;18: $342-348$.

60. Hsieh C-J, Wang P-W, Liu R-T, et al. Orlistat for obesity: benefits beyond weight loss. Diabetes Res Clin Pract. 2005;67:78-83.

61. Chan KW, Leung WS, Fung YS, et al. The effects of diet and orlistat on body weight and lipid profiles in high risk Chinese patients with coronary artery disease, obesity and hypercholesterolemia. Ir J Med Sci. 2009;178:173-178.

62. Madsen EL, Bruun JM, Skogstrand K, Hougaard DM, Christiansen T, Richelsen B. Long-term weight loss decreases the nontraditional cardiovascular risk factors interleukin-18 and matrix metalloproteinase-9 in obese subjects. Metabolism. 2009;58:946-953. 
63. Eriksson KF, Lindgärde F. No excess 12-year mortality in men with impaired glucose tolerance who participated in the Malmö Preventive Trial with Diet and exercise. Diabetologia. 1998;41: 1010-1016.

64. Yaari S, Goldbourt U. Voluntary and involuntary weight loss: associations with long-term mortality in 9,228 middle-aged and elderly men. Am J Epidemiol. 1998;148:546-555.

65. Diehr P, Bild DE, Harris TB, Duxbury A, Siscovick D, Rossi M. Body mass index and mortality in nonsmoking older adults: the Cardiovascular Health Study. Am J Public Health. 1998;88:623-629.

66. French SA, Folsom AR, Jeffery RW, Williamson DF. Prospective study of intentionality of weight loss and mortality in older women: the Iowa Women's Health Study. Am J Epidemiol. 1999;149: 504-514.

67. Gregg E, Gerzoff RB, Thompson TJ, Williamson DF. Intentional weight loss and death in overweight and obese US adults 35 years of age and older. Ann Intern Med. 2003;138:383-389.

68. Davidson MH, Hauptman J, DiGirolamo M, et al. Weight control and risk factor reduction in obese subjects treated for 2 years with orlistat. A randomized controlled trial. JAMA. 1999;281:235-242.

69. Svendsen M, Helgeland M, Tonstad S. The long-term influence of orlistat on dietary intake in obese subjects with components of metabolic syndrome. J Hum Nutr Diet. 2009;22:55-63.

70. Filippatos TD, Derdemezis CS, Kiortsis DN, Tselepis AD, Elisaf MS. Orlistat-associated adverse effects and drug interactions: a critical review. Drug Safety. 2008;31:53-65.

71. Yarlagadda SG, Perazella MA. Drug-induced crystal nephropathy: an update. Expert Opin Drug Safe. 2008;7:147-158.

72. Willemen MJ, Mantel-Teeuwisse AK, Straus SMJM, Leufkens HGM, Egberts ACG, Sturkenboom MCJM. Cardiovascular and psychiatric risk profile and patterns of use in patients starting anti-obesity drugs. Pharmacoepidemiol Drug Safe. 2009;7:631-638.

73. Perrio MJ, Wilton LV, Shakir SA. The safety profiles of orlistat and sibutramine: results of prescription-event monitoring studies in England. Obesity (Silver Spring). 2007;15(11):2712-2722.

74. Fabricatore AN, Wadden TA, Moore RH, et al. Attrition from randomized controlled trials of pharmacological weight loss agents: a systematic review and analysis. Obes Rev. 2009;10:333-341.

75. Padwal R, Kezouh A, Levine M, Etminan M. Long-term persistence with orlistat and sibutramine in a population-based cohort. Int J Obes. 2007;31:1567-1570.

76. Phelan S, Wadden TA. Combining behavioral and pharmacological treatments for obesity. Obes Res. 2002;10:560-574.

77. Wadden TA, Berkowitz RI, Womble LG, et al. Randomized trial of lifestyle modification and pharmacotherapy for obesity. NEJM. 2005;353:2111-2120.

78. Blanck HM, Kettel Khan L, Serdula MK. Diet and physical activity behavior among users of prescription weight loss medications. Int $J$ Behav Nutr Phys Act. 2004;I:17. Available at: http://www.ijbnpa.org/ content/I/I/17. Accessed October 2009.

79. Jay M, Kalet A, Ark T, et al. Physicians' attitudes about obesity and their associations with competency and specialty: A cross-sectional study. BMC Health Serv Res. 2009:9:106. Available at http:/www. biomedcentral.com/1472-6963/9/106. Accessed Mar 10, 2010.

80. Green LA, Fryer GEJ, Yawn BP, Lanier D, Dovey SM. The ecology of medical care revisited. N Engl J Med. 2001;344:2021-2025.

81. Bowerman S, Bellman M, Saltsman P, et al. Implementation of a primary care physician network obesity management program. Obes Res. 2001;9 Suppl 4:S321-S325.

82. Galuska DA, Will JC, Serdula MK. Are health care professionals advising obese patients to lose weight? JAMA. 1999;282:1576-1578.

83. Sciamanna CN, Tate DF, Lang W, Wing RR. Who reports receiving advice to lose weight? Results from a multi-state survey. Arch Int Med. 2000;160:2334-2339.

84. Thande NK, Hurstak EE, Sciacca RE, Giardina EGV. Management of obesity: a challenge for medical training and practice. Obesity. 2008;17:107-113.
85. Phelan S, Nallari M, Darroch F, Wing RR. What do physicians recommend to their overweight and obese patients? J Am Board Fam Med. 2009;22:115-122.

86. Foster GD, Wadden TA, Makris AP, et al. Primary care physicians' attitudes about obesity and its treatment. Obes Res. 2003;11: 1168-1177.

87. Foster GD, Wadden TA, Vogt RA, Brewer G. What is a reasonable weight loss? Patients' expectations and evaluations of obesity treatment outcomes. J Consult Clin Psychol. 1997;65:79-85.

88. Foster GD, Wadden TA, Phelan S, Sarwer DB, Sanderson RS. Obese patients' perceptions of treatment outcomes and the factors that influence them. Arch Intern Med. 2001;161:2133-2139.

89. Arnold M. GSK's launch of Alli is heavy on lifestyle messages. Med Mark Media. 2007;42:7.

90. Ippolito P, Pappalardo J. Advertising nutrition and health: evidence from food advertising, 1977-1997. Bureau of Economics Staff Report. Washington DC: Federal Trade Commission; 2002 Sept.

91. Neovius M, Narbro K. Cost-effectiveness of pharmacological anti-obesity treatments: a systematic review. Int J Obes. 2008;32: 1752-1763.

92. Maetzel A, Ruof J, Covington M, Wolf A. Economic evaluation of orlistat in overweight and obese patients with type 2 diabetes mellitus. Pharmacoeconomics. 2003;21:501-512.

93. Iannazzo S, Zaniolo O, Pradelli L. Economic evaluation of treatment with orlistat in Italian obese patients. Curr Med Res Opin. 2008; 24:63-74.

94. van Baal PHM, van den Berg M, Hoogenveen RT, Vijgen SM, Engelfriet PM. Cost-effectiveness of a low-calorie diet and orlistat for obese persons: modeling long-term health gains through prevention of obesity-related chronic diseases. Value Health. 2008;11:1033-1040.

95. Roux L, Kuntz KM, Donaldson C, et al. Economic evaluation of weight loss interventions in overweight and obese women. Obesity. 2006:14;1093-1105.

96. Foxcroft DR. Orlistat for the treatment of obesity: cost utility model. Obes Rev. 2005;6:323-328.

97. Foxcroft DR, Milne R. Orlistat for the treatment of obesity: rapid review and cost-effectiveness model. Obes Rev. 2000;1:121-126.

98. Must A, Jacques PF, Dallal GE, Bajema CJ, Dietz WH. Long-term morbidity and mortality of overweight adolescents. A follow-up of the Harvard Growth Study of 1922 to 1935. N Engl J Med. 1992;327: 1350-1355

99. Whitaker RC, Wright JA, Pepe MS, Seidel KD, Dietz WH. Predicting obesity in young adulthood from childhood and parental obesity. N Engl J Med. 1997;337:869-873.

100. Freedman DS, Kettle Khan L, Dietz WH, Srinivasan SR, Berenson GS. Relationship of childhood obesity to coronary heart disease risk factors in adulthood: the Bogalusa Heart Study. Pediatrics. 2001;108: 712-718.

101. Bray GA. Predicting obesity in adults from childhood and adolescent weight. Am J Clin Nutr. 2002;76:497-498.

102. Guo SS, Wu W, Chumlea WC, Roche AF. Predicting overweight and obesity in adulthood from body mass index values in childhood and adolescence. Am J Clin Nutr. 2002:76:653-658.

103. van Dam RM, Willett WC, Manson JE, Hu FB. The relationship between overweight in adolescence and premature death in women. Ann Intern Med. 2006;145:91-97.

104. Caprio S, Fennoy I, et al. The Endocrine Society. Prevention and treatment of pediatric obesity: an Endocrine Society clinical practice guideline. J Clin Endocrinol Metab. 2008;93:4576-4599.

105. American Heart Association. Overweight in children and adolescents: pathophysiology, consequences, prevention, and treatment. Circulation. 2005;111:1999-2012.

106. Dietz WH. What constitutes successful weight management in adolescents? Ann Intern Med. 2006;145:145-146.

107. Oude Luttikhuis H, Baur L, Jansen H, et al. Interventions for treating obesity in children. Cochrane Database of Systematic Reviews. 2009, Issue 1. Art. No.: CD001872. DOI: 10.1002/14651858.CD001872.pub2. 
108. McGovern L, Johnson JN, Paulo R, et al. Treatment of pediatric obesity: A systematic review and meta-analysis of randomized trials. J Clin Endocrinol Metab. 2008;93:4600-4605.

109. Shin L, Bregman H, Frasier J, Noyes N. An overview of obesity in children with psychiatric disorders taking atypical antipsychotics. Harvard Rev Psychiatry. 2008;16:69-79.

110. Mayer MA, Hocht C, Puyo A, Taira C. Recent advances in obesity pharmacotherapy. Curr Clin Pharmacol. 2009;4:53-61.

111. Blood Pressure Lowering Trialists' Collaboration. Effects of ACE inhibitors, calcium antagonists, and other blood-pressure-lowering drugs: results of prospectively designed overviews of randomised trials. Lancet. 2000;355:1955-1964.
112. Warden SJ, Fuchs RK. Are "exercise pills" the answer to the growing problem of physical inactivity? Br J Sports Med. 2008;42: $862-863$.

113. Hawley JA, Holloszy JO. Exercise: It's the real thing. Nutr Rev. 2009;67: $172-178$.

114. Roux L, Pratt M, Tengs TO, et al. Cost Effectiveness of CommunityBased Physical Activity Interventions. Am J Prev Med. 2008;35: $578-588$.

\section{Publish your work in this journal}

ClinicoEconomics \& Outcomes Research is an international, peerreviewed open-access journal focusing on Health Technology Assessment, Pharmacoeconomics and Outcomes Research in the areas of diagnosis, medical devices, and clinical, surgical and pharmacological intervention. The economic impact of health policy and health systems organization also constitute important areas of coverage. The manuscript management system is completely online and includes a very quick and fair peer-review system, which is all easy to use. Visit http://www.dovepress.com/testimonials.php to read real quotes from published authors.

Submit your manuscript here: http://www.dovepress.com/clinicoeconomics-and-outcomes-research-journal 